\title{
Food Safety, COVID-19 and Laboratory Testing
}

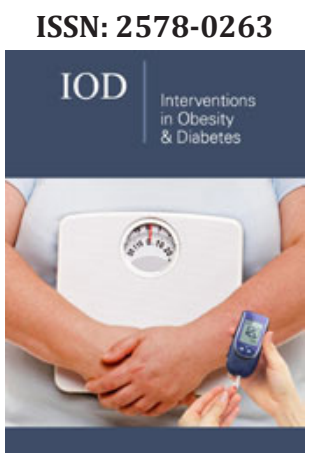

*Corresponding author: Carmine Finelli, $\mathrm{MD}, \mathrm{PhD}$, Department of Internal Medicine, Ospedale Cav R Apicella-ASL Napoli 3 Sud, Via di Massa, 1, 80040 Pollena (Napoli), Italy

Submission: 望-1 June 08, 2020

Published: 悳June 29, 2020

Volume 4 - Issue 3

How to cite this article: Carmine Finelli, Simone Dal Sasso, Lab Tech. Food Safety, COVID-19 and Laboratory Testing. Interventions Obes Diabetes 4(3). IOD.000586. 2020. DOI: 10.31031/IOD.2020.04.000586

Copyright@ Carmine Finelli, MD, PhD. This article is distributed under the terms of the Creative Commons Attribution 4.0 International License, which permits unrestricted use and redistribution provided that the original author and source are credited.

\author{
Carmine Finelli, MD, PhD ${ }^{1,2 *}$, and Simone Dal Sasso, Lab Tech ${ }^{3}$ \\ ${ }^{1}$ Department of Internal Medicine, Ospedale Cav R Apicella-ASL Napoli 3 Sud, Via di Massa, 1, 80040 \\ Pollena (Napoli), Italy \\ ${ }^{2}$ Covid Hospital Boscotrecase-ASL Napoli 3 Sud, Via Lenza, 3, 80042 Boscotrecase (Napoli), Italy. Email \\ address: carminefinelli74@yahoo.it \\ ${ }^{3}$ Independent Researcher, Naples, Italy
}

\section{Opinion}

The coronavirus disease 2019 (COVID-19) is believed to be transmitted by respiratory droplets from person to person [1]. There is usually no evidence to support the transmission of COVID-19 related with food [2]. It is important, for general food safety, to always wash your hands with soap and water for 20 seconds before preparing or eating food. Clean your hands all day after blowing your nose, crying, sneezing, or going to the toilet [3]. A human might be able to get COVID-19 by contacting a surface or an item that has the virus on it and then contacting their own mouth, nose, or likely eyes, but this is not considered to be the primary way the virus spreads [4]. Generally speaking, due to poor survivability of these coronaviruses on surfaces, the risk of spreading from food products or packaging is likely very low. It's important always handle and prepare food safely, including keeping raw meat separate from other foods, cooking meat at the right temperature to kill harmful germs. Scientists and food safety authorities around the world are closely monitoring the spread of COVID-19 [3,5]. By following safe food handling and cooking practices, we can reduce your risk of infection and kill the virus which causes COVID-19 [6]. We can use common methods for the washing and disinfection of coronaviruses and clean your hands at least 20 seconds before and after touching produce and product containers with soap and warm water [7]. It is possible use one of the licensed hand sanitizers if we do not have hot water. We can clean your vegetables and fruit under running water. It is not advised to wash fresh produce with ammonia, chlorine, or some other product. Fresh produce is porous and can absorb chemicals that you do not want to eat. Another, it is important to cook the food at the recommended safe inner temperature; ordinary cooking temperatures destroy coronaviruses; do not contaminate raw and ready-toeat or cooked foods and desinfect any surfaces coming into contact with food [7].

Using these strategies to keep us safe when shopping at grocery stores and carry home your groceries [8]. Using hand sanitizers at the shop entrance, if accessible. Take your own clean, reusable food bags (if allowed) or try utilizing bags offered at the supermarket outlet. Hold the distance from others when shopping. When out in public, particularly in crowded environments, wear a non-medical mask or face cover when it is not feasible to maintain a reasonable 2-meter physical distance from others. Evite touching items that you will not take. Avoid touching the eyes, mouth and nose. When leaving the shop, using hand sanitizers, if appropriate. Clean the hands upon getting home. Put away your shopping, particularly those things that need cooling. Clean the hands after handling preparing goods and foods. Use appropriate cooking and food handling practices. Using these tips to keep you safe while you are delivering food to your home. Wherever possible using contactless payment: key fob; pay online; tap and go, mobile payment; request contactless delivery where appropriate. Drop your food down at the doorstep. Keep the distance from the delivery person (a minimum of 2 arms lengths, around 2 meters). Clean your hands after delivery is completed [9]. Put away your shopping, particularly those things that need cooling. Wash your hands after handling 
preparing food. Using good instruction in the handling of foods. The issues that have not modified with covid19 are the need for internal or external laboratory suppliers to seek to maintain legal standards, and the fact that chemical and microbiological testing must remain a major part of industry-wide food safety programs [10]. For these needs and specifications, the laboratory needs to have world-class testing capabilities to help you handle improvements to the method and client expectations. Consider, for example, other areas where your contract laboratory can help you beyond the test, such as: trying to map and evaluation of environmental programs; brand review of innovative products and/or packages going from fast food to department stores; sensory study of different types of products or package sizes; desktop consultancy or online training for program and process review. Real collaborations on food protection require more than just delivering a test result. It is necessary to provide the knowledge and expertise required to give us the peace of mind to concentrate on our everyday business needs and deliver product, whilst our partner has the experience and tools to help you fulfill consumer expectations without diluting your attention on our core competencies.

In conclusion, we think we should get a message from the fact that we have accomplished a great deal in virology and food health, but wildlife-related food safety problems have become an omission. Every country has made tremendous investments in many areas, such as the military, education, communication, bank, etc. Even when you have accomplished a lot and spent a lot of money, that doesn't mean you 're not going to be reckless. Staff in all fields (nutritionists, laboratory technicians, biotechnology, etc.) will work together to catch up on the issues that have been neglected, for the sake of a better future for humanity. We say that, despite the fact that our ordinary profession is within the area of internal medicine and clinical nutrition and of biomedical laboratory technician.

\section{Acknowledgement}

Ludovica Dal Sasso, a English speaker, who has the entire manuscript proof read and supervised the linguistic revision.

\section{References}

1. Elbeddini A, Prabaharan T, Almasalkhi S, Tran C, Zhou Y (2020) Barriers to conducting deprescribing in the elderly population amid the COVID-19 pandemic. Res Social Adm Pharm S1551-7411(20)30602-1.

2. La Rosa G, Bonadonna L, Lucentini L, Kenmoe S, Suffredini E (2020) Coronavirus in water environments: occurrence, persistence and concentration methods-A scoping review. Water Res 179: 115899.

3. Galanakis CM (2020) The food systems in the era of the coronavirus (COVID-19) pandemic crisis. Foods 9(4): 523.

4. Rothan HA, Byrareddy SN (2020) The epidemiology and pathogenesis of coronavirus disease (COVID-19) outbreak. J Autoimmun 109: 102433.

5. Haghani M, Bliemer MCJ, Goerlandt F, Li J (2020) The scientific literature on coronaviruses, COVID-19 and its associated safety-related research dimensions: A scientometric analysis and scoping review. Saf Sci 129: 104806.

6. Xie X, Huang L, Li JJ, Zhu H (2020) Generational differences in perceptions of food health/risk and attitudes toward organic food and game meat: The case of the COVID-19 crisis in China. Int J Environ Res Public Health 17(9): 3148

7. Desai AN, Aronoff DM (2020) Food Safety and COVID-19. JAMA.

8. Moy GG (2020) IUFoST/CIFST hold an extraordinary scientific roundtable on COVID-19 and food safety. NPJ Sci Food 4: 8

9. Glauser W (2020) Proposed protocol to keep COVID-19 out of hospitals. CMAJ 192(10): E264-E265.

10. Yang DM, Chang TJ, Wang ML, Tsai PH, Lin TH, et al. (2020) Hunting coronavirus SARS-CoV-2 (2019-nCoV): from laboratory testing back to basic research. J Chin Med Assoc. 